ARTICLE

https://doi.org/10.1038/s41467-019-11398-0

\title{
Sulfenamide-enabled ortho thiolation of aryl iodides via palladium/norbornene cooperative catalysis
}

\author{
Renhe Li (1) ${ }^{1}$, Yun Zhou ${ }^{1}$, Ki-Young Yoon ${ }^{1}$, Zhe Dong (i) ${ }^{2} \&$ Guangbin Dong (i) ${ }^{1}$
}

Poly-substituted aromatic sulfur compounds are widely found in pharmaceuticals, agrochemicals and organic materials. However, the position that a sulfur moiety can be introduced to is largely restricted to a pre-functionalized site; otherwise, use of electronically biased substrates or auxiliary groups that direct catalysis is required. Here we report a general ortho thiolation of common aryl and heteroaryl iodides via palladium-norbornene cooperative catalysis. Using this approach, an aryl or alky sulfur moiety can be site-selectively introduced at the arene ortho position without using sterically or electronically biased substrates. The arene ipso functionalization is simultaneously achieved through Heck, Suzuki or Sonogashira termination. The reaction is enabled by a unique class of electrophiles in palladium-norbornene cooperative catalysis, which are sulfenamides derived from sevenmembered lactams. The broad substrates scope and high chemoselectivity could make this method attractive for synthesis of complex sulfur-containing aromatic compounds.

\footnotetext{
${ }^{1}$ Department of Chemistry, University of Chicago, Chicago, IL 60637, USA. ${ }^{2}$ Merck Center for Catalysis at Princeton University, Princeton, NJ 08544, USA. Correspondence and requests for materials should be addressed to Z.D. (email: wdzdao@gmail.com) or to G.D. (email: gbdong@uchicago.edu)
} 
A romatic sulfur compounds are commonly found in drugs $^{1}$, agrochemicals ${ }^{2}$, organic electronics ${ }^{3}$, and polymers $^{4}$ (Fig. 1a). In addition, aryl sulfides often serve as versatile intermediates to access the corresponding sulfoxides ${ }^{5}$, sulfones ${ }^{6}$, and benzothiophenes ${ }^{7}$. Common ways to prepare aryl sulfides heavily rely on nucleophilic aromatic substitution ${ }^{8}$ and cross-coupling reactions $s^{9}$ between aryl halides and thiols. Both methods form carbon-sulfur (C-S) bonds at the ipso position of aryl halides; thus, the position of the installed sulfur moiety is restricted by the position of the halide. On the other hand, $\mathrm{C}-\mathrm{H}$ thiolation offers an attractive approach to introduce sulfur to an non-pre-functionalized position; ${ }^{10}$ however, control of siteselectivity generally requires use of directing groups ${ }^{11,12}$ or electron-rich arenes ${ }^{13}$. Hence, a general method that siteselectively introduces sulfur functional groups to unbiased and unactivated arene positions would be highly attractive for preparing multi-substituted aromatic sulfur compounds. This has motivated us to explore the approach using palladium/norbornene $(\mathrm{Pd} / \mathrm{NBE})$ cooperative catalysis.

Pd/NBE cooperative catalysis ${ }^{14-16}$, originally discovered by Catellani ${ }^{17}$, has emerged as a useful tool for preparing multisubstituted arenes ${ }^{18-33}$. Compared to the conventional arene functionalization, this approach enables simultaneous functionalization of arene vicinal positions regioselectively using simple aryl halides as substrates (Fig. 1b). Specifically, through forming an aryl-NBE-palladacycle (ANP) intermediate, a nucleophile and an electrophile are coupled at the arene ipso and ortho positions, respectively. While the scope of nucleophiles in this reaction is broad $^{14-16}$, finding suitable electrophiles that can participate in the Catellani reaction nevertheless remains a formidable challenge ${ }^{34,35}$, because the electrophile must react with ANP selectively in the presence of $\operatorname{Pd}(0)$ species and has to be compatible with the nucleophile and NBE. Currently, the scope of electrophiles is mainly limited to carbon ${ }^{17,36-41}$ and nitrogen ${ }^{42}$. based reagents. In 2017, Yu used aryl chlorosulfates for a directed Pd(II)-catalyzed meta chlorination of arenes; ${ }^{43}$ however, compatibility of this reagent with $\operatorname{Pd}(0)$ catalysts could be a concern ${ }^{44}$.
More recently, Zhang ${ }^{45}$ and Cheng ${ }^{46}$ independently reported an interesting ortho silyation with disilanes; unfortunately, NBE cannot be extruded in this reaction. Clearly, it would be attractive if other elements, besides $\mathrm{C}$ and $\mathrm{N}$, could be introduced at the arene ortho position in the $\operatorname{Pd}(0)$-catalyzed Catellani reaction. Herein, we report a Pd/NBE-catalyzed ortho thiolation of aryl iodides, which is enabled by sulfenamide-type electrophiles (Fig. 1c). This approach provides a general platform to introduce various sulfur moieties to the arene ortho positon and simultaneously install other functional groups at the arene ipso position. The generality, scability and high chemoselectivity could make this method attractive for preparing complex sulfur-containing aromatic compounds.

\section{Results}

Hypothesis. Compared to other ortho functionalizations, ortho thiolation exhibits its unique challenges. First, many electrophilic sulfur-based compounds, such as $\mathrm{PhSSPh}$ or $\mathrm{PhSCl}$, readily react with $\operatorname{Pd}(0)^{47}$, therefore preventing arene functionalization. Second, thiolates (RS-) are known as strong ligands for soft Pd species; thus, decomposition of the thiolation agent would likely generate $\mathrm{RS}^{-}$that could lead to direct ipso thiolation ${ }^{48}$. Hence, developing a stable but also reactive electrophilic thiolation agent would be a key for realizing the ortho thiolation reaction. Based on our prior efforts on developing the ortho amination reaction ${ }^{42}$, sulfenamides ${ }^{49,50}$ were anticipated to be a suitable electrophile for the $\mathrm{Pd} / \mathrm{NBE}$ catalysis for two reasons (Fig. 1d): (1) the electronegativity ( $E_{\text {neg }}$, Pauling scale) difference between $\mathrm{N}$ and $\mathrm{S}$ matches well with that between $\mathrm{O}$ and $\mathrm{N} ;^{51}$ (2) analogous to the ortho amination, the amide carbonyl could serve as a directing moiety to facilitate selective reactions with ANP. Thus, we hypothesized that sulfenamides might show similar stability and reactivity as O-benzoyl hydroxylamines. It is noteworthy that, during the review process of this work, an interesting ortho thiolation using thiosulfonate reagents was reported by $\mathrm{Gu}^{52}$.

\section{Ortho thiolation via Pd/NBE catalysis}

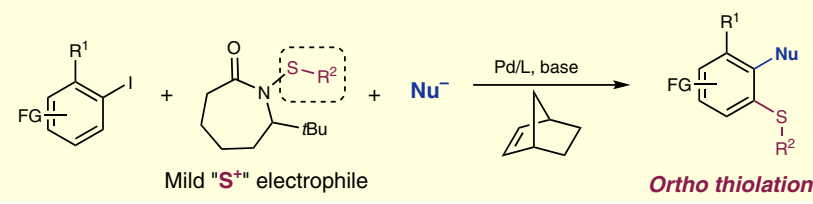

d Reaction design

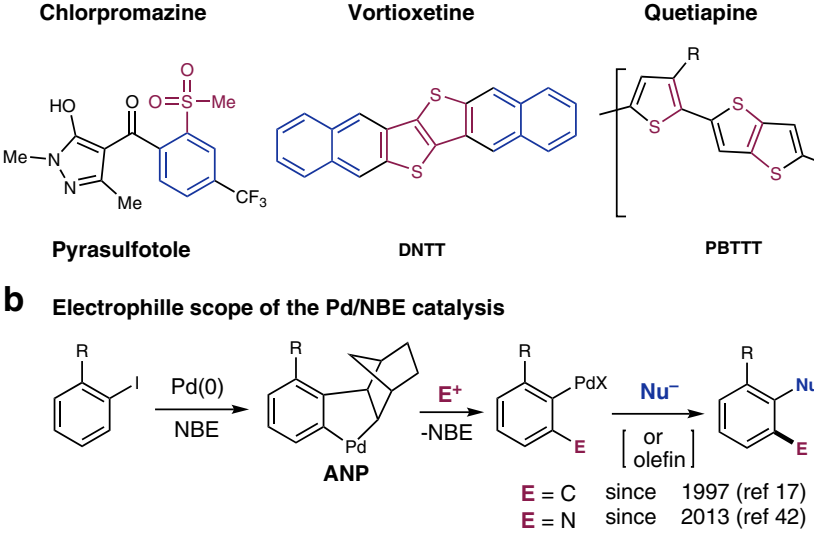

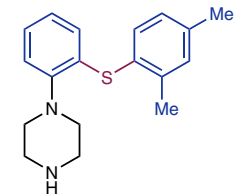

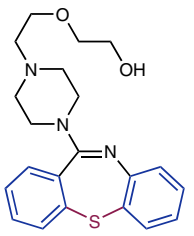

Quetiapine
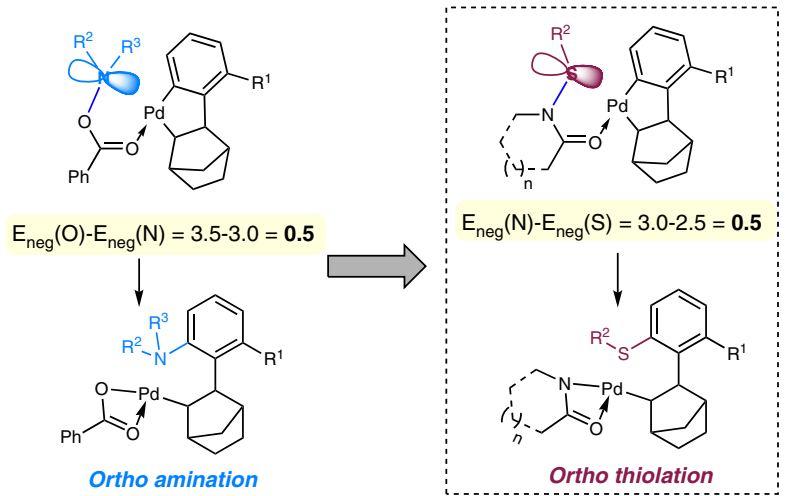

Fig. 1 Project background and design for ortho $\mathrm{C}-\mathrm{H}$ thiolation via Pd/NBE cooperative catalysis. a Important drugs, agrochemicals, organic electronics, and polymers that contain aryl-sulfur bonds. $\mathbf{b}$ Established ortho functionalization of aryl iodides with different electrophiles via Pd/NBE cooperative catalysis. c This work describes an ortho thiolation using sulfenamides as the electrophilic thiolation reagent. $\mathbf{d}$ Design of ortho $\mathrm{C}-\mathrm{H}$ thiolation reagents. E electrophile, Nu nucleophile, $E_{\text {neg }}$ electronegativity 


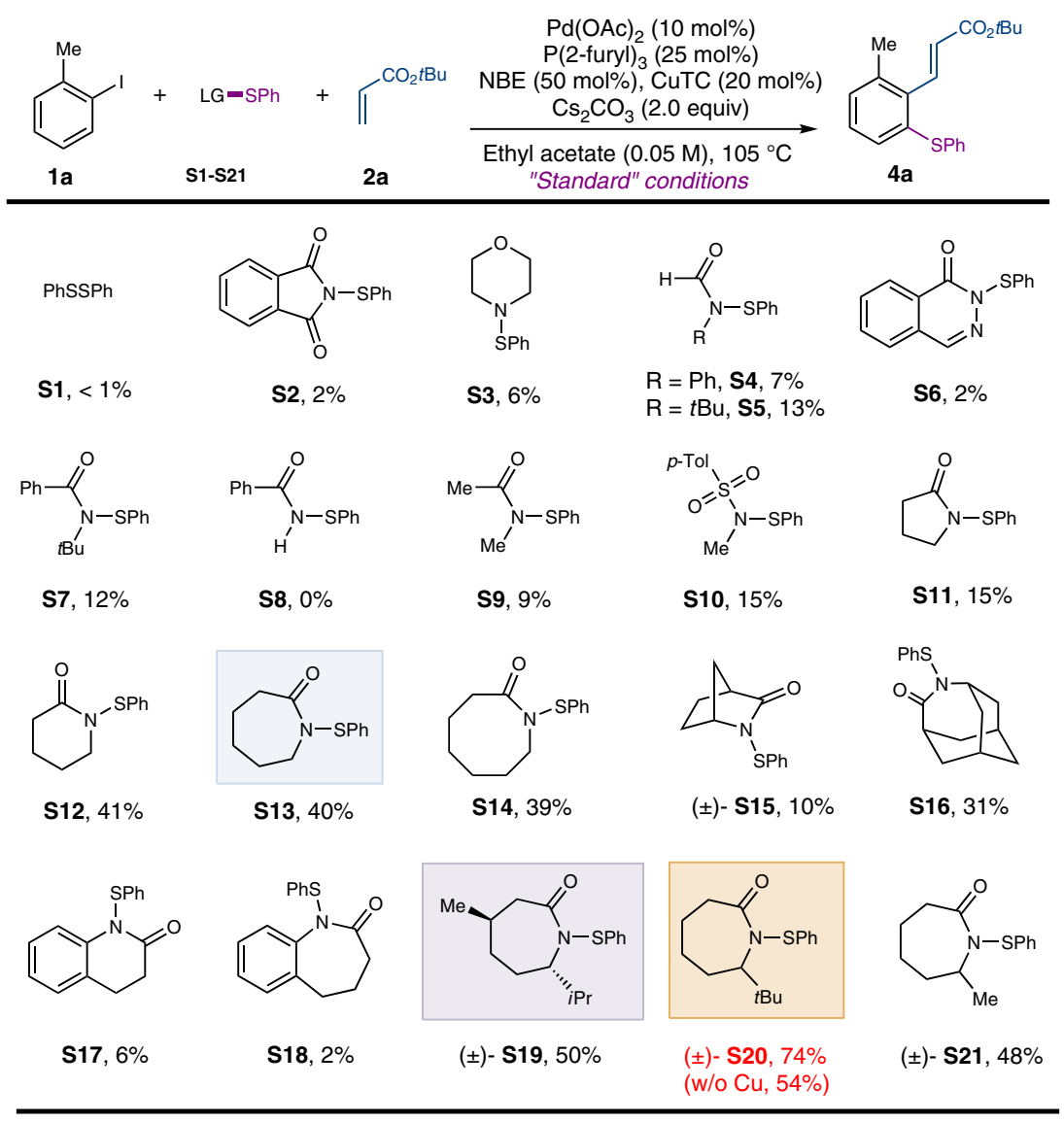

Fig. 2 Electrophiles for the Pd/NBE-catalyzed ortho thiolation of aryl iodides. The reaction was run with $1(0.15 \mathrm{mmol}), 2(0.30 \mathrm{mmol})$, sulfur electrophile $(0.30 \mathrm{mmol}), \mathrm{Pd}(\mathrm{OAc})_{2}(0.015 \mathrm{mmol}), \mathrm{P}(2 \text {-furyl })_{3}(0.0375 \mathrm{mmol}), \mathrm{NBE}(0.075 \mathrm{mmol}), \mathrm{Cs}_{2} \mathrm{CO}_{3}(0.30 \mathrm{mmol})$, and CuTC (0.03 mmol) in ethyl acetate $\left(3.0 \mathrm{~mL}\right.$ ) at $105^{\circ} \mathrm{C}$ for $12 \mathrm{~h}$. The yield was determined by ${ }^{1} \mathrm{H}-\mathrm{NMR}$ using 1,3,5-trimethoxylbenzene as the internal standard. LG leaving group, CuTC copper (I) thiophene-2-carboxylate<smiles>C#C[Sb]N1CCCC1=O</smiles><smiles>C#C[SnH]N1CCCCCC1=O</smiles><smiles>C#C[Pb]N1CCCCC1=O</smiles><smiles></smiles>

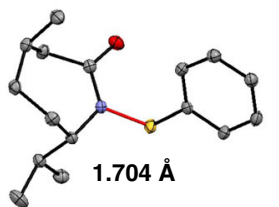
( \pm - $\mathrm{S} 19$<smiles>C#C[Sb]N1CCCCCC1=O</smiles>

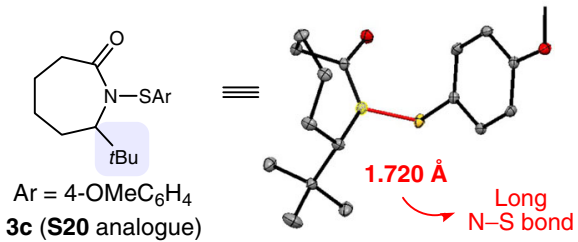

Fig. 3 X-ray structures of selected lactam-derived sulfenamides. The nitrogen-sulfur bond lengths are labeled in ångström ( $\AA$ )

Optimization of reaction conditions. To test this hypothesis, a range of sulfenamide-based thiolation agents were examined with 2iodotoluene (1a) as the standard substrate, and the ipso position was functionalized via Heck termination with acrylate 2a (Fig. 2). As a control experiment, PhSSPh S1, previously used in the Pd-catalyzed $\mathrm{C}-\mathrm{H}$ thiolation ${ }^{11,12}$, gave almost no desired product with a low conversion of 1a. In contrast, various sulfenamides indeed afforded the desired ortho thiolation product (4a). First, neither imidederived or amine-derived sulfenamides (S2 and S3) were as effective as amide-based ones. In particular, the lactam-derived sulfenamides (S11-S21) were found most reactive. Interestingly, the six, seven, and eight-membered sulfenamides (S12-S14) gave significantly improved yields compared to the five-membered one (S11). Use of more strained or benzofused lactams (S15-S18) gave inferior results. Surprisingly, increasing the bulkiness around the lactam nitrogen with an adjacent isopropyl group significantly enhanced the yield (S19). Ultimately, the optimal result was obtained using the tert-butyl-substituted sulfenamide S20. 


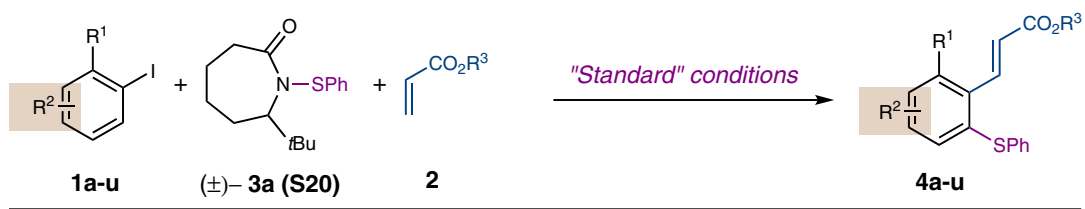

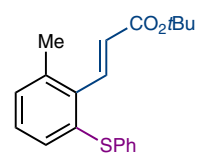

4a, $75 \%$<smiles>CC(=O)OCc1cccc(-c2ccccc2)c1C=COC(C)(C)C</smiles>

$4 e, 74 \%$<smiles>CCCCOC(=O)C=Cc1c(OC)cccc1Sc1ccccc1</smiles>

4b, $71 \%$<smiles>CCCCOCc1cccc(S)c1/C=C/C(=O)OCC(C)(C)C</smiles><smiles>CCCCOC(=O)/C=C/c1c(OCc2ccc(Br)cc2)cccc1-c1ccccc1</smiles>

4c, $52 \%$ 4d, $57 \%$

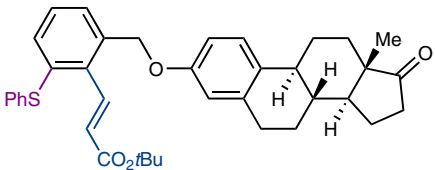

4f, $56 \%$

$4 g, 47 \%$<smiles></smiles><smiles>CC(=O)/C=C/c1c(C)cc(Br)cc1Sc1ccccc1</smiles><smiles>CON(C)C(=O)c1cc(-c2ccccc2)c(/C=C/C(C)=O)c([N+](C)(C)C)c1</smiles><smiles>CCCCOC(=O)C=Cc1c(C)cc(N2CCOCC2)cc1-c1ccccc1</smiles>

4h, $59 \%$

4i, $55 \%$

4k, $70 \%$

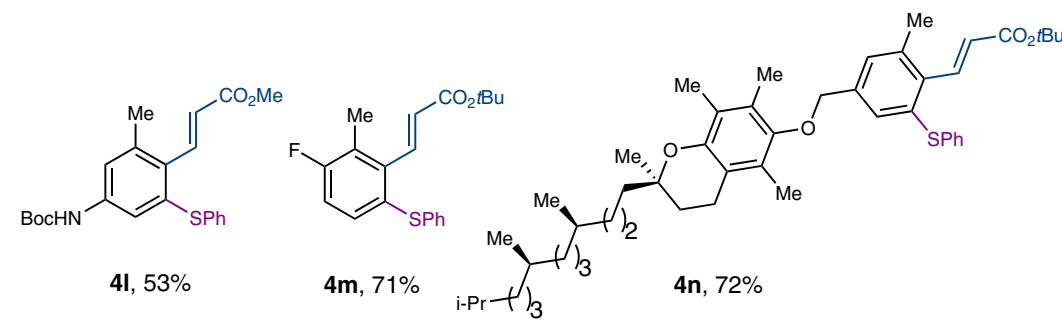<smiles>CC(=O)C=Cc1c(-c2ccccc2)ccc2ncccc12</smiles>

4o, $90 \%$<smiles>COC(=O)/C=C/c1c(-c2ccccc2)cc(OC)c2ncccc12</smiles>

4p, $59 \%$<smiles>O=C(O)/C=C/c1c([PbH])ccc2[nH]ccc12</smiles>

4q, $40 \%$<smiles>O=C(O)/C=C/c1c(S)csc1O</smiles>

$4 r, 36 \%$<smiles>CC(C)(C)OC=Cc1c(-c2ccccc2)ccc2ccccc12</smiles>

4s, $93 \%$<smiles>CCC(C)OC(=O)C=Cc1c(-c2ccccc2)c2ccccc2c2ccccc12</smiles>

4t, $45 \%$<smiles>CCCCOC(=O)C=Cc1c(-c2ccccc2)cc2ccc3cccc4ccc1c2c34</smiles>

4u, $91 \%$

Fig. 4 The aryl iodide scope of the ortho thiolation. All reactions were run with $0.2 \mathrm{mmol} \mathbf{1}, 0.4 \mathrm{mmol} \mathbf{3 a}(\mathbf{S 2 0})$, and $0.4 \mathrm{mmol} \mathbf{2}$ in ethyl acetate (0.5 M) at $105^{\circ} \mathrm{C}$ for $12 \mathrm{~h}$. Isolated yields are reported. For detailed experimental procedure, see Supplementary Fig. 4

To understand these counterintuitive results in terms of the role of the bulk substituent, X-ray crystal structures of S11-S14, S19 and S20 analog (3c) were obtained (Fig. 3 and Supplementary Figs. 10-16). A clear trend is that increasing the steric hindrance around the amide moiety elongated the N-S bond, which correlates to the performance of these reagents. Hence, the tert-butyl group in $\mathbf{S 2 0}$ weakened the $\mathrm{N}-\mathrm{S}$ bond, thereby making it more reactive. Note that adding copper(I) thiophene-2carboxylate $(20 \mathrm{~mol} \%)$ enhanced the yield, which may serve as a thiolate scavenger (for full control experiments, see Supplementary Table 1).
Substrates scope of aryl iodide. With the optimized conditions in hands, the aryl iodide scope was examined first (Fig. 4). Different substituents at the ortho position of aryl iodides were tolerated, including methyl (4a), methoxy (4b), MOM ether (4c), 4-bromobenzyl ether (4d), acetate and silyl-protected benzyl alcohols (4e and $\mathbf{4 f}$ ), and an estrone derivative (4g). In addition, a broad range of functional groups were compatible, such as aryl chloride (4h), aryl bromide (4i), Weinreb amide (4j), dialkyl aniline (4k), carbamate (4l), fluoride (4m), and Vitamin E moiety (4n). Importantly, the reaction is suitable for a variety of heteroarenes and polycyclic arenes, including quinoline derivative 

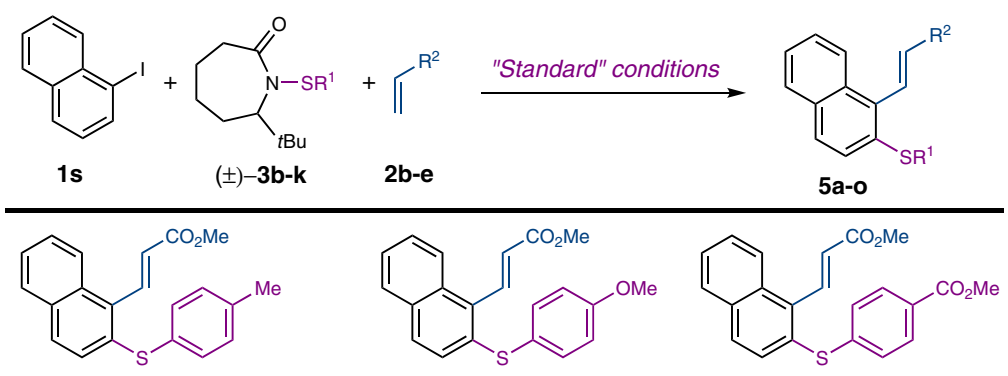

5a, $86 \%$

5b, $71 \%$

5c, $82 \%$<smiles>CC(=O)C=Cc1c(Sc2ccc(F)cc2)ccc2ccccc12</smiles><smiles>COC(C)=CCc1c(Sc2ccc(Cl)cc2)ccc2ccccc12</smiles><smiles>CC(=O)/C=C/c1c(Sc2ccc(Br)cc2)ccc2ccccc12</smiles>

5d, $93 \%$

5 e, $87 \%$

5f, $86 \%$<smiles>CC(=O)C=Cc1c(Sc2ccc(C(F)(F)F)cc2)ccc2ccccc12</smiles>

5g, $85 \%$<smiles>CC(=O)C=Cc1c(Sc2ccc3ccccc3c2)ccc2ccccc12</smiles><smiles>CC(=O)C=Cc1c(Sc2ccccc2[N+](=O)[O-])ccc2ccccc12</smiles>

5h, $91 \%$<smiles>CC(=O)/C=C/c1c(Sc2cccc(F)c2)ccc2ccccc12</smiles>

5i, $92 \%$<smiles>COc1ccc2ccccc2c1/C=C/C(C)=O</smiles>

5k, $40 \%^{a}$

lefin scope<smiles>CCCCOC(=O)/C=C/c1c(-c2ccccc2)ccc2ccccc12</smiles>

5I, $84 \%$<smiles>CCOC(=O)/C=C/c1c(-c2ccccc2)ccc2ccccc12</smiles>

$5 \mathrm{~m}, 87 \%$<smiles>CC(=O)C=Cc1c(-c2ccccc2)ccc2ccccc12</smiles>

5n, $88 \%$<smiles>CC(=O)C=Cc1c(-c2ccccc2)ccc2ccccc12</smiles>

5o, $93 \%$

Fig. 5 The sulfenamide and olefin scope of the ortho thiolation. All reactions were run with $0.2 \mathrm{mmol} \mathbf{1 s}, 0.4 \mathrm{mmol} \mathbf{3}$ and $0.4 \mathrm{mmol} \mathbf{2}$ in ethyl acetate (0.5 M) at $105{ }^{\circ} \mathrm{C}$ for $12 \mathrm{~h}$. Isolated yields are reported. a Sulfenamide $\mathbf{6}$ was used instead of 3. For detailed experimental procedure, see Supplementary Fig. 4

(4o and 4p), indole (4q), thiophene (4r), naphthalene (4s), phenanthrene $(\mathbf{4 t})$, and pyrene $(\mathbf{4 u})$.

Substrates scope of thiolation agents. Next, the scope of the thiolation agents and the olefin coupling partners was explored (Fig. 5). Besides PhS-, other aryl sulfur groups that contain electron-donating or withdrawing groups could be introduced at the ortho position in good to excellent yields. Notably, the orthosubstituted aryl sulfide (5h) still afforded a high yield of product. While it was challenging to prepare the corresponding alkyl thiolation agents based on the $t \mathrm{Bu}$-substituted lactam, use of simple $\varepsilon$-lactam-derived sulfenamide 6 nevertheless delivered the desired methylthiolated product $(\mathbf{5 k})$ in moderate efficiency. In addition to $t \mathrm{Bu}$ acrylate, other acrylates and acrylamides (5l-5o) were also competent coupling partners for ipso functionalization.

Synthetic application. From a practical viewpoint, the lactam byproduct 3a' was recovered in $86 \%$ yield after the reaction, which could be used to regenerate the sulfenamide reagent (Fig. 6a). The reaction is scalable: a high yield was still obtained on a gram scale (Fig. 6b). Besides aryl sulfides, the corresponding sulfoxides and sulfones could be conveniently accessed through selective oxidation of the ortho thiolation product (Fig. 6c). In addition to Heck coupling, preliminary success has been obtained with Suzuki quench
(Fig. 6d) and Sonogashira quench (Fig. 6e) to install an aryl group or alkyne group at the ipso position, respectively ${ }^{14-16}$.

\section{Discussion}

In summary, a unique class of electrophilic thiolation reagents, sulfenamides, is developed for the Pd/NBE catalysis, which enables ortho thiolation of a wide range of aryl and heteroaryl iodides. The broad substrate scope, scalability, and high chemoselectivity could make this method attractive for complex molecule synthesis. The substituent effect observed in tuning the sulfenamide reactivity could have implications beyond this work. Efforts on expanding the reaction scope and understanding the detailed mechanism of the $\mathrm{C}-\mathrm{S}$ bond formation are underway.

\section{Methods}

General procedure of the Pd/NBE-catalyzed ortho thiolation. To a flame-dried $7.0 \mathrm{~mL}$ vial (vial A) was added palladium acetate $(4.6 \mathrm{mg}, 0.02 \mathrm{mmol}, 10 \mathrm{~mol} \%)$, copper(I) thiophene-2-carboxylate (7.6 mg, $0.04 \mathrm{mmol}, 20 \mathrm{~mol} \%)$, tri(2-furyl) phosphine (11.6 mg, $0.05 \mathrm{mmol}, 25 \mathrm{~mol} \%)$, and aryl iodide $(0.2 \mathrm{mmol}, 1.0$ equiv). The thiolation agent $(0.6 \mathrm{mmol})$ was added to another $4.0 \mathrm{~mL}$ vial (vial B). These two vials were then transferred into a nitrogen-filled glovebox without caps. In glovebox, cesium carbonate ( $130.4 \mathrm{mg}, 0.4 \mathrm{mmol}, 2.0$ equiv) was added to vial A before a solution of norbornene in dry ethyl acetate $(0.5 \mathrm{~mL}$ $0.1 \mathrm{mmol}$ ) was transferred to the same vial. To the $4.0 \mathrm{~mL}$ vial B containing thiolation agent was added $0.75 \mathrm{~mL}$ dry ethyl acetate, and then two thirds of 
a

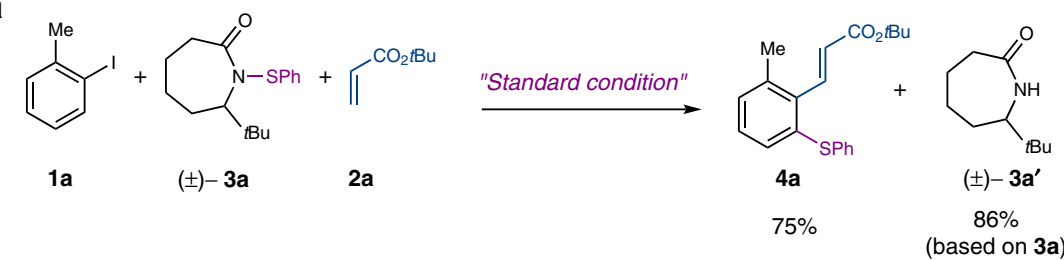

b

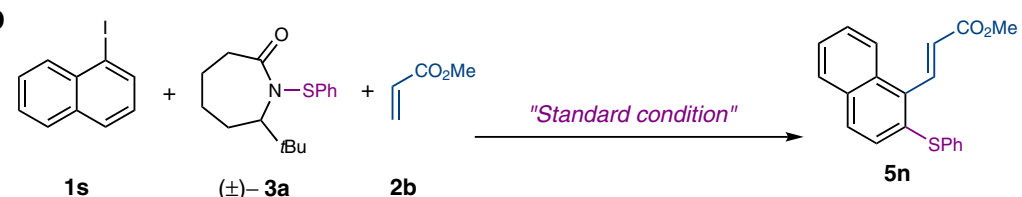

$1.36 \mathrm{~g}, 85 \%$

C

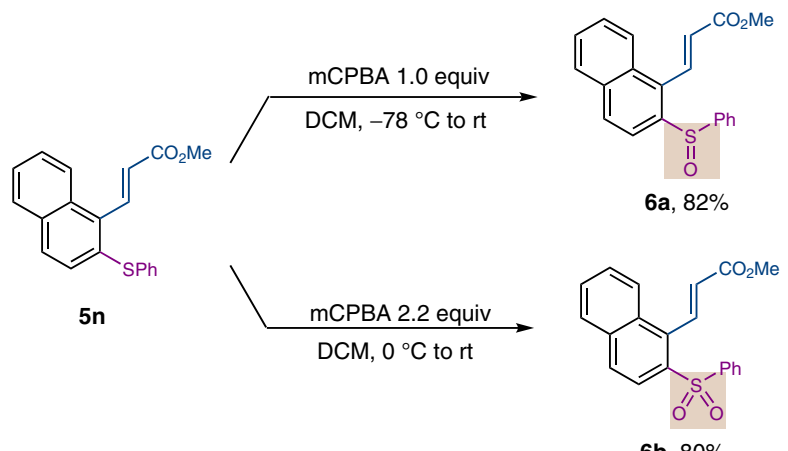

d<smiles>O=C1CCCC([18F])N([PH3+])C1=O</smiles>

1s

$( \pm)-3 a$<smiles>CC1(C)COB(c2ccccc2)OC1</smiles>

8

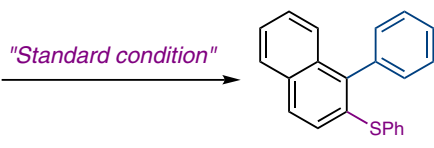

9, $58 \%$

e

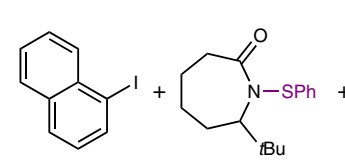

1s<smiles>CC#CC(C)(C)O</smiles>

10

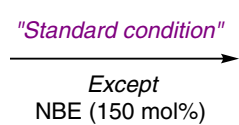

NBE $(150 \mathrm{~mol} \%)$

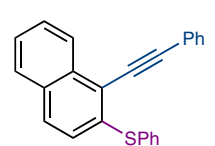

$11,51 \%$

Fig. 6 Synthetic applications. a Recovery of lactam 3a'. b Gram scale reaction. c Selective oxidation of an aryl sulfide to a sulfoxide and a sulfone. d Ipso functionalization via Suzuki coupling. e Ipso functionalization via Sonogashira coupling

this solution $(0.5 \mathrm{~mL}, 0.4 \mathrm{mmol}, 2.0$ equiv) was transferred into vial $\mathrm{A}$, before another $3.0 \mathrm{~mL}$ dry ethyl acetate and acrylate $2(0.4 \mathrm{mmol}, 2.0$ equiv) were added. Vial A was then tightly sealed, transferred out of glovebox and stirred on a pie-block preheated to $105^{\circ} \mathrm{C}$ for $12 \mathrm{~h}$. After completion of the reaction, the mixture was filtered through a thin pad of silica gel. The filter cake was washed with ethyl acetate and the combined filtrate was concentrated under vacuum. The residue was purified via silica gel chromatography to yield the desired ortho thiolation product.

\section{Data availability}

Experimental procedures (Supplementary Figs. 1-9) and characterization data (Supplementary Figs. 10-149) are available within this article and Supplementary Information. CCDC: 1906766 (S11), 1906767 (S12), 1906768 (S13), 1906770 (S14), 1906771 (S19), 1906769 (3c), and 1906772 (4e) contain the supplementary crystallographic data for this paper. These data can be obtained free of charge from the Cambridge Crystallographic Data Center via www.ccdc.cam.ac.uk/data_request/cif.

Received: 16 April 2019 Accepted: 12 July 2019

Published online: 07 August 2019

\section{References}

1. Feng, M., Tang, B., H. Liang, S. \& Jiang, X. Sulfur containing scaffolds in drugs: synthesis and application in medicinal chemistry. Curr. Top. Med. Chem. 16, 1200-1216 (2016).

2. Devendar, P. \& Yang, G.-F. Sulfur-containing agrochemicals. Top. Curr. Chem. 375, 82 (2017).

3. Lee, E. K., Lee, M. Y., Park, C. H., Lee, H. R. \& Oh, J. H. Toward environmentally robust organic electronics: approaches and applications. $A d v$. Mater. 29, 1703638 (2017).

4. Roncali, J. Conjugated poly(thiophenes): synthesis, functionalization, and applications. Chem. Rev. 92, 711-738 (1992).

5. Varma, R. S. \& Naicker, K. P. The urea-hydrogen peroxide complex: solidstate oxidative protocols for hydroxylated aldehydes and ketones (dakin reaction), nitriles, sulfides, and nitrogen heterocycles. Org. Lett. 1, 189-192 (1999).

6. Voutyritsa, E., Triandafillidi, I. \& Kokotos, C. G. Green organocatalytic oxidation of sulfides to sulfoxides and sulfones. Synthesis 49, 917-924 (2017).

7. Tobisu, M., Masuya, Y., Baba, K. \& Chatani, N. Palladium(ii)-catalyzed synthesis of dibenzothiophene derivatives via the cleavage of carbon-sulfur and carbon-hydrogen bonds. Chem. Sci. 7, 2587-2591 (2016).

8. Terrier, F. in Modern Nucleophilic Aromatic Substitution Ch. 4, 205-278 (John Wiley \& Sons, Inc., Weinheim, German 2013). 
9. Beletskaya, I. P. \& Ananikov, V. P. Transition-metal-catalyzed C-S, C-Se, and $\mathrm{C}-\mathrm{Te}$ bond formation via cross-coupling and atom-economic addition reactions. Chem. Rev. 111, 1596-1636 (2011).

10. Vásquez-Céspedes, S., Ferry, A., Candish, L. \& Glorius, F. Heterogeneously catalyzed direct $\mathrm{C}-\mathrm{H}$ thiolation of heteroarenes. Angew. Chem. Int. Ed. $\mathbf{5 4}$ 5772-5776 (2015).

11. Iwasaki, M. et al. Palladium-catalyzed direct thiolation of aryl $\mathrm{C}-\mathrm{H}$ bonds with disulfides. Chem. Eur. J. 20, 2459-2462 (2014).

12. Lin, C., Li, D., Wang, B., Yao, J. \& Zhang, Y. Direct ortho-thiolation of arenes and alkenes by nickel catalysis. Org. Lett. 17, 1328-1331 (2015).

13. Saravanan, P. \& Anbarasan, P. Palladium catalyzed aryl(alkyl)thiolation of unactivated arenes. Org. Lett. 16, 848-851 (2014).

14. Ye, J. \& Lautens, M. Palladium-catalysed norbornene-mediated C-H functionalization of arenes. Nat. Chem. 7, 863-870 (2015).

15. Della, Ca',N., Fontana, M., Motti, E. \& Catellani, M. Pd/Norbornene: a winning combination for selective aromatic functionalization via $\mathrm{C}-\mathrm{H}$ bond activation. Acc. Chem. Res. 49, 1389-1400 (2016).

16. Wang, J. \& Dong, G. Palladium/norbornene cooperative catalysis. Chem. Rev. 119, 7478-7528 (2019).

17. Catellani, M., Frignani, F. \& Rangoni, A. A complex catalytic cycle leading to a regioselective synthesis of o,o'-disubstituted vinylarenes. Angew. Chem. Int. Ed. 36, 119-122 (1997).

18. Lautens, M. \& Piguel, S. A new route to fused aromatic compounds by using a palladium-catalyzed alkylation-alkenylation sequence. Angew. Chem. Int. Ed. 39, 1045-1046 (2000).

19. Bressy, C., Alberico, D. \& Lautens, M. A route to annulated indoles via a palladium-catalyzed tandem alkylation/direct arylation reaction. J. Am. Chem. Soc. 127, 13148-13149 (2005).

20. Jiao, L. \& Bach, T. Palladium-catalyzed direct 2-alkylation of indoles by norbornene-mediated regioselective cascade $\mathrm{C}-\mathrm{H}$ activation. J. Am. Chem. Soc. 133, 12990-12993 (2011).

21. Sui, X., Zhu, R., Li, G., Ma, X. \& Gu, Z. Pd-catalyzed chemoselective catellani ortho-arylation of iodopyrroles: rapid total synthesis of rhazinal. J. Am. Chem. Soc. 135, 9318-9321 (2013).

22. Zhang, H., Chen, P. \& Liu, G. Palladium-catalyzed cascade C?H trifluoroethylation of aryl iodides and heck reaction: efficient synthesis of ortho-trifluoroethylstyrenes. Angew. Chem. Int. Ed. 53, 10174-10178 (2014).

23. Wang, X.-C. et al. Ligand-enabled meta-C-H activation using a transient mediator. Nature 519, 334-338 (2015).

24. Dong, Z., Wang, J. \& Dong, G. Simple amine-directed meta-selective C-H arylation via pd/norbornene catalysis. J. Am. Chem. Soc. 137, 5887-5890 (2015).

25. Lei, C., Jin, X. \& Zhou, J. Palladium-catalyzed heteroarylation and concomitant ortho-alkylation of aryl iodides. Angew. Chem. Int. Ed. 54, 13397-13400 (2015)

26. Shi, H., Babinski, D. J. \& Ritter, T. Modular C-H functionalization cascade of aryl iodides. J. Am. Chem. Soc. 137, 3775-3778 (2015).

27. Sun, F. et al. Cleavage of the $\mathrm{C}(\mathrm{O})-\mathrm{S}$ bond of thioesters by palladium/ norbornene/copper cooperative catalysis: an efficient synthesis of 2-(Arylthio) aryl ketones. J. Am. Chem. Soc. 138, 7456-7459 (2016).

28. Wang, J., Li, R., Dong, Z., Liu, P. \& Dong, G. Complementary site-selectivity in arene functionalization enabled by overcoming the ortho constraint in palladium/norbornene catalysis. Nat. Chem. 10, 866-872 (2018).

29. Dong, Z., Lu, G., Wang, J., Liu, P. \& Dong, G. Modular ipso/ortho difunctionalization of aryl bromides via palladium/norbornene cooperative catalysis. J. Am. Chem. Soc. 140, 8551-8562 (2018).

30. Zhang, B.-S. et al. Carboxylate ligand-exchanged amination/C(sp3)-H arylation reaction via $\mathrm{Pd} /$ norbornene cooperative catalysis. ACS Catal. 8, 11827-11833 (2018).

31. Wang, Z. et al. Expeditious synthesis of 6-fluoroalkyl-phenanthridines via palladium-catalyzed norbornene-mediated dehydrogenative annulation. Org. Lett. 20, 6640-6645 (2018).

32. Li, R., Liu, F. \& Dong, G. Redox-neutral ortho functionalization of aryl boroxines via palladium/norbornene cooperative catalysis. Chem 5, 929-939 (2019).

33. Liu, F., Dong, Z., Wang, J. \& Dong, G. Palladium/norbornene-catalyzed indenone synthesis from simple aryl iodides: concise syntheses of pauciflorol $\mathrm{F}$ and acredinone A. Angew. Chem. Int. Ed. 58, 2144-2148 (2019).

34. Liu, Z.-S., Gao, Q., Cheng, H.-G. \& Zhou, Q. Alkylating reagents employed in catellani-type reactions. Chem. Eur. J. 24, 15461-15476 (2018).

35. Zhao, K., Ding, L. \& Gu, Z. Development of new electrophiles in palladium/ norbornene-catalyzed ortho-functionalization of aryl halides. Synlett 30, 129-140 (2019).

36. Faccini, F., Motti, E. \& Catellani, M. A new reaction sequence involving palladium-catalyzed unsymmetrical aryl coupling. J. Am. Chem. Soc. 126, 78-79 (2004)

37. Zhou, P.-X. et al. Palladium-catalyzed acylation/alkenylation of aryl iodide: a domino approach based on the catellani-lautens reaction. ACS Catal. 5, 4927-4931 (2015)
38. Dong, Z., Wang, J., Ren, Z., Dong, G. \& Ortho, C. -H. Acylation of aryl iodides by palladium/norbornene catalysis. Angew. Chem. Int. Ed. 54, 12664-12668 (2015)

39. Huang, Y., Zhu, R., Zhao, K. \& Gu, Z. Palladium-catalyzed catellani orthoacylation reaction: an efficient and regiospecific synthesis of diaryl ketones. Angew. Chem. Int. Ed. 54, 12669-12672 (2015).

40. Wang, J., Zhang, L., Dong, Z. \& Dong, G. Reagent-enabled orthoalkoxycarbonylation of aryl iodides via palladium/norbornene catalysis. Chem 1, 581-591 (2016)

41. Li, R. \& Dong, G. Direct annulation between aryl iodides and epoxides through palladium/norbornene cooperative catalysis. Angew. Chem. Int. Ed. 57, 1697-1701 (2018).

42. Dong, Z. \& Dong, G. Ortho vs Ipso: site-selective Pd and norbornenecatalyzed arene $\mathrm{C}-\mathrm{H}$ amination using aryl halides. J. Am. Chem. Soc. 135, 18350-18353 (2013).

43. Shi, H., Wang, P., Suzuki, S., Farmer, M. E. \& Yu, J.-Q. Ligand promoted meta-C-H chlorination of anilines and phenols. J. Am. Chem. Soc. 138, 14876-14879 (2016).

44. DeBergh, J. R., Niljianskul, N. \& Buchwald, S. L. Synthesis of aryl sulfonamides via palladium-catalyzed chlorosulfonylation of arylboronic acids. J. Am. Chem. Soc. 135, 10638-10641 (2013).

45. Ma, X., Lu, A., Ji, X., Shi, G. \& Zhang, Y. Disilylation of palladacycles that were generated through the $\mathrm{C}-\mathrm{H}$ activation of aryl halides. Asian J. Org. Chem. 7, 1403-1410 (2018)

46. Lv, W., Wen, S., Yu, J. \& Cheng, G. Palladium-catalyzed ortho-silylation of aryl iodides with concomitant arylsilylation of oxanorbornadiene: accessing functionalized $(Z)-\beta$-substituted vinylsilanes and their analogues. Org. Lett. 20, 4984-4987 (2018).

47. Kuniyasu, H., Sugoh, K., Su, M. S. \& Kurosawa, H. The first evidence of insertion of isocyanide into a metal-sulfur bond: catalytic and stoichiometric behavior of isocyanide and thiolate ligands on palladium and platinum. J. Am. Chem. Soc. 119, 4669-4677 (1997).

48. Baranano, D. \& Hartwig, J. F. Carbon-heteroatom bond-forming reductive elimination. mechanism, importance of trapping reagents, and unusual electronic effects during formation of aryl sulfides. J. Am. Chem. Soc. 117, 2937-2938 (1995)

49. Zhang, X.-S., Li, G., Zhang, X.-G. \& Zhang, X.-H. Pd(II)-catalyzed selective sulfenylation of arene $\mathrm{C}-\mathrm{H}$ bonds using $\mathrm{N}$-arylthiobenzamides as thiolation reagent and oxidant. Tetrahedron 71, 5458-5464 (2015).

50. Craine, L. \& Raban, M. The chemistry of sulfenamides. Chem. Rev. 89, 689-712 (1989).

51. Pauling, L. The nature of the chemical bond. IV. the engergy of single bonds and the relative electronegativity of atoms. J. Am. Chem. Soc. 54, 3570-3582 (1932).

52. Cai, W. \& Gu, Z. Selective ortho thiolation enabled by tuning the ancillary ligand in palladium/norbornene catalysis. Org. Lett. 21, 3204-3209 (2019).

\section{Acknowledgements}

Financial supports from the University of Chicago and NIGMS (1R01GM124414-01A1) are acknowledged. Y.Z. thanks CSC for a fellowship. Mr. Jianchun Wang is acknowledged for helpful discussions.

\section{Author contributions}

Z.D. discovered the transformation and performed the preliminary optimization. R.L. and Y.Z. performed the optimization, subsrate scope and synthetic applications. K.Y. performed the X-ray crystallography study. G.D. guided the project. Z.D. and G.D conceived the idea and wrote the paper with input from all authors. All authors analyzed the results and commented on the paper.

\section{Additional information}

Supplementary Information accompanies this paper at https://doi.org/10.1038/s41467019-11398-0.

Competing interests: The authors declare no competing interests.

Reprints and permission information is available online at http://npg.nature.com/ reprintsandpermissions/

Peer review information: Nature Communications thanks Yongmin Liang, Bolin Zhu and other anonymous reviewer(s) for their contribution to the peer review of this work. Peer reviewer reports are available.

Publisher's note: Springer Nature remains neutral with regard to jurisdictional claims in published maps and institutional affiliations. 
(c) (i) Open Access This article is licensed under a Creative Commons Attribution 4.0 International License, which permits use, sharing, adaptation, distribution and reproduction in any medium or format, as long as you give appropriate credit to the original author(s) and the source, provide a link to the Creative Commons license, and indicate if changes were made. The images or other third party material in this article are included in the article's Creative Commons license, unless indicated otherwise in a credit line to the material. If material is not included in the article's Creative Commons license and your intended use is not permitted by statutory regulation or exceeds the permitted use, you will need to obtain permission directly from the copyright holder. To view a copy of this license, visit http://creativecommons.org/ licenses/by/4.0/.

(C) The Author(s) 2019 